\title{
Implementation of Comprehensiveness Principle in Evaluation of the Public Procurement System Efficiency
}

\author{
Volkova A.G.* \\ Voronezh branch of the Russian Academy of national \\ economy and public administration under the President of \\ the Russian Federation \\ Voronezh, Russia \\ e-mail: ppivolk@mail.ru \\ Sabetova T.V. \\ Voronezh State Agrarian University \\ Voronezh, Russia \\ e-mail: tsabetova@mail.ru \\ Iureva A.A. \\ Voronezh State Agrarian University \\ Voronezh, Russia \\ e-mail: artemida_donna@mail.ru
}

\author{
Pyl'tsyna M.V. \\ Voronezh State Agrarian University \\ Voronezh, Russia \\ e-mail: pmvistoria@mail.ru
}

\author{
Sivolapova E.A. \\ Voronezh State Agrarian University \\ Voronezh, Russia \\ e-mail: dimanin83@mail.ru \\ Altukhova E.V. \\ Voronezh State Agrarian University \\ Voronezh, Russia
}

\begin{abstract}
The subject of the study is the evaluation of the effectiveness of the public procurement system. The aim of the work was the formation of a procedure for assessing the effectiveness of the public procurement system. The article systematizes the problems of public procurement management for the needs of federal state unitary enterprises and other organizations, including those essential for ensuring the rights and legitimate interests of citizens of the Russian Federation, the defense capability, and security of the state. As a result of the study, the following tasks were solved. 1 . The necessity of designing a procedure for assessing the effectiveness of the public procurement system was considered and substantiated; 2 . The essence and concept of the procedure for assessing the effectiveness of the public procurement system is demonstrated; 3. The theoretical principles of designing the procedure for the effectiveness of the public procurement system are formulated and the main categories are explained; 4 . The procedure for performing an expert assessment is proposed; 5 . The algorithm for assessing the effectiveness of the public procurement system is presented and explained, and 6. The general concept of its materialization is formulated. The article proposes to consider a comprehensive indicator of the effectiveness of the public procurement system as a high-quality, practice-oriented, and theoretically substantiated assessment of the effectiveness of the public procurement system based on the principle of comprehensiveness. The proposed procedure is holistic and logical, it allows the widespread use of national statistics, which are distinguished by a high degree of reliability and verification, and therefore provide a high-quality, practice-oriented, and theoretically justified assessment of the effectiveness of the public procurement system.
\end{abstract}

Keywords - governmental procurement, contractual system, legislation, public companies, evaluation procedure, analytic assessment, budget economy.

\section{INTRODUCTION}

The relevance of the organization of the procurement process to meet public needs in federal institutions is due to a number of circumstances. Public procurement has traditionally been one of the drivers of the domestic economy, and this is not only about the last decades. However, in Russia over the past decade, a number of laws and guidelines have been enacted that regulate the mechanism of state and municipal procurements and transfer them to a competitive basis, but more often they were characterized by internal inconsistency and incompleteness.

Enactment and application of the Federal law dated April 5, 2013, \#44-FZ "Concerning the contractual system in the area of goods, work, service procurement for state and municipal needs" [1], unfortunately, have not yet solved numerous legal and organizational problems of procurement. The application of this law entails significant punitive sanctions in the form of administrative fines against legal and official customers.

The procurement contract system for the needs of public companies, especially for those essential for ensuring the rights and legitimate interests of citizens of the Russian Federation, the defense capability and security of the state often includes mutually exclusive elements that must be balanced. This is the need to combine the openness and transparency of public procurement and at the same time keep secret the information that could be used later by a potential 
adversary against the Russian Federation, including the protection of state secrets.

The efficiency of spending budget funds directly depends on the strict implementation of all the procedures provided for by the contract system in the field of procurement and the preparation of relevant documentation to ensure control over the quality of their implementation [2]. The preparation of a significant amount of documents in conjunction with the regular change in the procedure for conducting procurement procedures greatly complicates the activities of public customers, and sometimes does not at all make it possible to solve the tasks assigned to them. Meanwhile avoiding compliance with procurement procedures, in turn, makes it difficult to ensure economic efficiency.

\section{LITERATURE REVIEW}

Federal law "Concerning alterations to certain legal acts of the Russian Federation in terms of purchasing goods, works, services state and municipal needs of specific types of legal entities" dated July $3^{\text {rd }}$, 2016, \#321-FZ bound all state unitary enterprises to make their purchases goods, works, services strictly in accordance with the Law \#44-FZ, including in its part concerning disclosure of the information about their procurement [3].

In this regard, it became necessary to make exceptions for federal state unitary enterprises that are essential for ensuring the rights and legitimate interests of citizens of the Russian Federation, the defense capability, and security of the country. The separation of federal state unitary enterprises into a special category, which are essential for ensuring the rights and legitimate interests of citizens of the Russian Federation, the defense capability, and security of the country, has allowed prevention of the loss of flexibility and efficiency of actions in the conditions required for timely and high-quality solution of tasks. This did not cause any decrease in procurement efficiency, but at the same time retained the requirements for compliance with specific procedures.

This decision turned out to be an effective tool to support the activities of state unitary enterprises, which were able to substantiate before the Government of the Russian Federation their essential importance for ensuring the rights and legitimate interests of citizens of the Russian Federation or for the defense and security of the country by providing the ability to meet their needs through less "overregulated" procurement procedures.

The Decree of the Government of the Russian Federation "Concerning the specifics of procurement for the needs of the national defense and security of the country" dated November 27, 2017, \# 1428 [4] with further amendments became a considerable change in the contractual system of procurement. This Decree defines the specifics of procurement for the Ministry of Defense of the Russian Federation, the Federal Security Service of the Russian Federation, the Foreign Intelligence Service of the Russian Federation, as well as state institutions and state unitary enterprises subordinate to them. The essence of innovation consists in the obligation to use closed methods for identifying suppliers (contractors, contractors).
In connection with the changes made, these executive bodies and their subordinate state institutions and state unitary enterprises, in the case of the procurement of goods, works, services included in the List, as well as other goods, works, services through an electronic auction are required to hold a closed auction using the functionality of a specialized electronic platform, the operator of which is an automated trading system of the state defense order" (hereinafter referred to as the specialized electronic platform).

The specialized electronic platform did not provide a sufficient degree of competition for tenders, since the majority of procurement participants who had previously participated in tenders at the main electronic platforms were not accredited at this site.

For the further improvement of the Decree \# 1428 Federal law "Concerning alterations to the Federal law "Concerning the contractual system in the area of goods, work, service procurement for state and municipal needs" was enacted on December $31^{\text {st }}, 2017$, \#504-FZ, which permanently fixed the obligation of the federal executive bodies, performing development and implementation of the national policy in the area of defense, public control of national security of the Russian Federation, their subordinate entities, state unitary enterprises, to use only closed methods of supplier (contractor) selection, except for the cases stated in Part 2 Art. 84.1 of Law \# 44-FZ (the list of the entities, organizations, and enterprises is appointed by the Government of the Russian Federation) [5].

Thus, the cost-effectiveness of electronic procurement methods has been experimentally confirmed [6], consisting in the savings between the planned contract prices and the value of real transactions, as well as a significant increase in the number of potential suppliers (contractors) participating in procurement, regardless of the number of customer invitations.

\section{Methodology}

All the previously developed many methods aimed at identifying the level of effectiveness of public procurement, we are convinced, can be attributed to one of two approaches that differ significantly from each other: either analytical or operational. Various researchers have repeatedly analyzed the operational approach to determining the effectiveness of public procurement, during which they highlighted and examined in detail its shortcomings and weaknesses, including in the light of the enactment of the new Federal Law \#44-FZ. If we make a brief summary of these studies, then among the most important shortcomings it was pointed out that the operational method makes the main emphasis, and to a certain extent allows one to quickly evaluate only one efficiency parameter when concluding a contract, which is the amount of budgetary savings. In no case do we deny its significance, but we insist that such an assessment is insufficient and one-sided. On the other hand, a group of analytical methods involves the development and application of a full range of measures used to evaluate all parameters of procurement, that is, in fact, introduces a systematic approach to assessing its effectiveness. This approach seems preferable to us, although it is obviously much more time-consuming. 


\section{ASSESSMENT METHODOLOGY}

Taking into consideration the already accumulated practical experience in the field of execution of the state order, a detailed study of the analytical group of methods for assessing the effectiveness of the contract system was conducted [7]. The first difficulty in the study was the lack of a clear definition of the very concepts of "analytical evaluation of public procurement" or "analytical methods for assessing the effectiveness of public procurement". The closest in meaning to the definition was the definition of the term "analytical assessment", however, it is of a much broader concept, which formed the methodological basis of the study. In the academic literature, it is interpreted as a set of methods that allow one to group, classify, and compare various objects, in particular, activities, taking into account their various characteristics: complexity, duration, a number of persons involved, other factors that may to some extent affect the qualitative characteristics of these objects. Based on this definition, it was proposed to narrow and specify it for the specific term "analytical evaluation of public procurement," which should be interpreted as a group of analysis methods based on a systematic approach, including a set of benchmarks (indicators) developed for the specific purpose of the study to form the final comprehensive criterion for public procurement efficiency [8].

In the analytical evaluation in the field of public procurement, various criteria are widely used; however, six of them are most indicative and popular among researchers:

- budget savings, already mentioned earlier, the importance of which we not only do not deny, but also emphasize in every way;

- compliance with legal norms and requirements, which allows us to evaluate not only the economic, but also the social effect of public procurement;

- share of competitive procurement, the importance of which is determined by the essence of the FCS, which is emphasized among the principles of the FCS in Art. 8 of Law \#44-FZ;

- fulfillment of plans when placing orders, as this allows the executives to fully satisfy the existing state needs that underlie these plans;

- discipline of contract execution, which to some extent echoes paragraph (ii), but has a more pronounced economic nature;

- validity of determining the initial contract prices.

It is important to emphasize that each of the 6 listed criteria has an unambiguous quantitative assessment, which in the future allows one to apply mathematical actions, including reducing them into a single formula for calculating the integral efficiency indicator.

For the generalized assessment of the weighted impact of each of the factors of the effectiveness of procurement activities, the calculation of the complex indicator $K(\mathrm{f} 6)$ was proposed. For its actual calculation, it is required to add the pre-calculated or taken from national statistics values of indicators for each factor, however, it is also necessary to take into account the unevenness of their influence on the total efficiency, for which weights are introduced, as shown in the formula (1):

$$
\mathrm{K}(\mathrm{f} 6)=0,3 \mathrm{~F} 1+0,1 \mathrm{~F} 2+0,2 \mathrm{~F} 3+0,1 \mathrm{~F} 4+0,1 \mathrm{~F} 5+0,2 \mathrm{~F} 6,
$$

where the procedure of assessment of the factors F1-F6 is demonstrated below.

The presented procedure for assessing the above six main factors that make up a comprehensive assessment of the effectiveness of the federal contractual system, in our opinion, is holistic and logical, it allows the widespread use of national statistics that are highly reliable and verifiable, and therefore provide high-quality, practice-oriented, and theoretically justified assessment of the effectiveness of the public procurement system.

After considering all the factors that determine the effectiveness of the public procurement system, taken into account in the proposed procedure for quantifying this effectiveness, we can visually present the elements of the process of assessing the effectiveness of the public procurement system (table 01 ).

TABLE I. THE ELEMENTS OF THE PROCESS OF ASSESSING THE EFFECTIVENESS OF THE PUBLIC PROCUREMENT SYSTEM

\begin{tabular}{|l|l|}
\hline \multicolumn{1}{|c|}{ Elements } & \multicolumn{1}{c|}{ Understanding } \\
\hline $\begin{array}{l}\text { Budget savings in } \\
\text { procurement (F1) }\end{array}$ & $\begin{array}{l}\text { characterizes the potential of the federal contract } \\
\text { system as a way to save the country's budget }\end{array}$ \\
\hline $\begin{array}{l}\text { Compliance with the } \\
\text { legislation controlling } \\
\text { the federal contractual } \\
\text { system (F2) }\end{array}$ & characterizes risks for all participants \\
\hline $\begin{array}{l}\text { Share of competitive } \\
\text { procurement (F3) }\end{array}$ & $\begin{array}{l}\text { characterizes the state of the field of healthy } \\
\text { competition in the sphere of meeting state needs }\end{array}$ \\
\hline $\begin{array}{l}\text { Fulfilment of planned } \\
\text { parameters in order } \\
\text { placement (F4) }\end{array}$ & characterizes the level of balance and predictability \\
\hline $\begin{array}{l}\text { Discipline of contract } \\
\text { execution (F5) }\end{array}$ & $\begin{array}{l}\text { characterizes the efficiency of the system at the } \\
\text { stage of practical implementation of the contract }\end{array}$ \\
\hline $\begin{array}{l}\text { Validity of determining } \\
\text { the initial contract } \\
\text { prices (F6) }\end{array}$ & $\begin{array}{l}\text { is an indicator of the correct determination of the } \\
\text { initial contract price }\end{array}$ \\
\hline
\end{tabular}

In order for the procurement of state institutions to be as effective as possible, the responsible persons should take measures to optimize procurement activities by systematizing the methodological and practical basis of activities [9]. In our opinion, the implementation of the proposed measures to improve the procurement process to meet the national needs in federal and other institutions will accelerate the development of the contractual system in the Russian Federation, better and more efficiently organize purchases to state customers, and allow fewer mistakes and violations in the activities of customers.

\section{ANALYSIS}

We named the budget savings in procurement as the first indicator F1. We put it in first place for two reasons. Firstly, it has the greatest weight $(0.3)$, that is, it is important for evaluating the system. Secondly, this indicator is used in all previously used methods, and in some cases even acted as the 
sole criterion of effectiveness, which emphasizes both its significance and the wide experience of its application and interpretation. It describes the potential of the federal contractual system as a way to save the national budget. However, the following innovation was proposed in this procedure: it is not recommended to take the initial maximum price of the contract as a basis for comparison, since errors and violations associated with, in particular, the corruption component are possible in its determination. For the base, we can take other values, for example, average industry prices of the similar transactions between commercial companies, prices of offers of industry players and others, available from commercial and public sources. Of course, we do not claim that determining the initial maximum price of a contract is absolutely always erroneous; moreover, violations in this area are largely prevented by the detailed instructions for setting such a price that are prescribed in Law \#44-FZ. However, we insist that the initial price cannot be considered the only and infallible reference point when it comes to the amount of budget savings achieved, and should not be used as such for a more accurate consideration of risks in public procurement [10].

We named the factor of compliance with the legislation regulating the federal contractual system as the second factor F2, which is calculated as simple as possible. We deduct those contracts that were concluded with violations, and therefore canceled after the violations are identified, from the total number of contracts made during the reporting period, and then divide the difference by the total number of contracts and express as a percentage. There are two possible ways of calculating it: by the number of contracts and by the amount; we consider the second method to be more accurate, but not mandatory. The importance of this factor for building an effective contractual system is difficult to dispute, since minimizing violations and abuses in this area directly reduces its risks for all participants. However, we have assigned this factor a weight of 0.1 , not 0.2 or 0.3 , which is due to our doubts about the possibility of a fully reliable quantitative assessment of the indicator. Indeed, far from all violations actually occurring in the public procurement system are certainly detected. Moreover, sometimes violations are detected after the expiration of the reporting period, and distort the indicators of the next period. That is, the violation occurred, for example, in the first quarter of the year (if the quarter was used as the reporting period), but reported and considered by the procurement statistics in the third quarter, to which the void contract itself has nothing to do, since, quite possibly, it had even been partially executed or fulfilled until that moment. It is natural to assume that the longer the period is taken for the reporting period, the more accurately the value of this indicator will be calculated. For example, to identify a violation during the year is not only possible, but also necessary, but if the reporting period is a month, then this indicator, without taking into account violations of past periods, will almost certainly be zero.

Scheduled inspections of public procurement contracts are relatively rare, therefore the main source of information for identifying violations is complaints. It should also be emphasized that the statute of limitations for abuses and violations in government contracts is set by law to six years, and therefore, if the reporting period for the analysis of procurement activities adopted for this purpose, for example, is five years, then this factor virtually loses its meaning.

We also point out the fact that the statistics of appeals and complaints to the FAS regarding violations in the field of public procurement show that some of these complaints after verification turn out to be unreasonable, and in some areas the proportion of unreasonable appeals reaches $40-50 \%$.

Thus, it is not always possible to correctly assess the effectiveness of the procurement system by the number of offenses. Therefore, as an alternative indicator, one can use the ratio of appeals and complaints, which turned out to be substantiated, to the total number of claims, since such an indicator directly indicates the quality of work of authorized bodies with the claims of participants in the federal contractual system.

Indicator F3, "share of competitive purchases", was adopted as an indicator of the share of purchases made using one of the competitive methods (mainly, of course, auctions and tenders), in their total volume. It should be noted that it can be used both in relation to the entire set of purchases in the state for a given period of time, and in relation to one specific supplier or customer, if necessary. It is widely acknowledged that the formation of a field of fair competition in the field of satisfying state needs is one of the main goals of the development and improvement of the federal contractual system, and therefore, ceteris paribus, it is desirable that the numerical value of this indicator grows. Its economic importance is manifested in the case when the use of competitive forms of procurement allows reduction of the amount of purchase costs in comparison with the initial price of the contract. However, although the share of purchases from a single supplier identifies the preservation of noncompetitive purchases, its size cannot be unambiguously interpreted as a measure of the system's inefficiency, since for any purchases there are also transaction costs, which in most cases turn out to be the highest when applying tenders and the lowest when purchasing from a single supplier.

Nevertheless, the importance of this indicator for assessing the system as a whole is difficult to dispute, and therefore it was assigned a weight of 0.2 , that is, higher than that of indicator F2. The only controversial point regarding this indicator, in our opinion, is the fact that, according to the provisions of Federal Law \#94-FZ of July $21^{\text {st }}, 2005$, a request for quotations was recognized as a non-competitive form of supplier selection. In Federal Law \#44-FZ this contradiction has been corrected; therefore, the procedure for calculating this parameter based on it seems to us more accurate.

The indicator of the fulfillment of the plans, in other words, the achievement of planned parameters when placing orders, indicated in the formula as F4, was assigned a weight coefficient of 0.1 . In general, this parameter allows not only to evaluate the effectiveness of the system, but to reveal the degree of its balance and predictability. It can, like the previous indicator, be used both in relation to the entire set of purchases in the state during a given period of time, and in relation to one specific supplier or customer. When calculating 
it, both refusals from the planned procurement procedures, as well as additional, unscheduled, emergency purchases, as well as a purely temporary factor - transfers or delays during the procurement operations are taken into consideration.

Although the weight assigned to this indicator is low, we do not deny the importance of this parameter, especially from the point of view of the opportunity it presents to quantitatively measure the qualitative characteristics of managerial processes in the field of public procurement, since planning is the main management function, and its quality is reflected in the indicator under consideration.

Considering that public procurement plans are drawn up within the framework of budgets, and accordingly, the planning horizon is a period of 1 or 3 years, this planning should be considered operational or medium-term. However, part of the procurement is carried out according to strategic plans, for example, as part of priority national programs. Thus, this indicator allows one to evaluate the quality of planning and management at the periods of various duration.

Part of public procurement, even carried out as part of annual plans, is carried out as a strategic management function, since individual procurement operations are interconnected within the framework of large-scale and longterm activities that generate those state needs that are satisfied gradually within the framework of the procurement process.

We would like to additionally justify the low weight coefficient assigned to this indicator in our formula. Although, as a characteristic of the quality of procurement planning and management in general, it seems to be very significant, its quantitative value is significantly affected by external influences. Adjustment of procurement plans may be required due to a number of external circumstances, both related to the economic situation and natural events (for example, natural disasters, etc.). These factors are neither subjects to the controlling influence of the subject being evaluated, nor they are anywhere near easy to predict. Consequently, an indicator cannot be unambiguously regarded only as an indicator of the quality of management: even with competent management, its value may turn out to be low.

The discipline of contract execution, which we designated in the formula as factor F5, also received a weight coefficient of 0.1 . This criterion allows us to evaluate the effectiveness of the system at the other chronological stage: not placement, but the practical implementation of a contract. When assessing it, we judge from the consideration that the main objective of the FCS is not just savings, transparency, or anti-corruption, but primarily the satisfaction of state needs and requirements. All the rest is the conditions, tools, but not the objective of the system as it is. Therefore, to assess the effectiveness of the work of the FCS, an indicator is needed that allows evaluation of precisely the degree of the needs' satisfaction, that is, the very fact of the contractual performance, the timing, quality, compliance with all the declared characteristics. Despite the low weight coefficient, this indicator seems to us the most necessary in the formula, and its low weight is explained by the fact that to a certain extent its value depends on the other factors presented in it, that is, from the point of view of calculus, it can be considered as secondary. Nevertheless, its exclusion makes the whole formula completely meaningless. No matter how competent, economical, legally flawless conclusion of contracts was, if as a result the necessary benefit was not received by the customer, all the work loses its meaning.

Finally, the last factor taken into account in the formula and designated in it as F6 was the validity of determining the initial maximum contract price. Numerically, it equals the difference between the initial maximum price of the contract and the size of the industry average price for a similar product (service, work). Therefore, we consider it a fairly reliable indicator of the correctness of determining the initial price of a contract. We do not dispute the assertion that in some cases the use of the industry average price as the starting price does not seem correct or even possible. Indeed, sometimes government structures need goods or services, analogues of which simply do not and cannot exist in the commercial market, for example, in the defense industries or in space exploration. However, in other situations, setting the initial price of the contract without taking into account the market situation, is either arbitrarily, based on personal experience and the opinions of officials, or based on the existing budgetary allocations, and it seems to us extremely undesirable. The validity of these considerations is confirmed simply by the fact that in Federal Law \#44-FZ explicit requirements appeared for substantiating the initial maximum price of a contract. To some extent, this change associated the indicator in question with parameter F2. The legislation regulates the methods for determining the initial maximum price, and neglecting them in public procurement is a violation of law, and the contracts made in right way are quantified in parameter F2. On the other hand, these violations can be detected already after the conclusion of the contract, or even during or at the end of its implementation, while the verification of the validity of determining the initial price is carried out before the start of all other procedures suggested by the FCS. Hence, on the one hand, the value of index F6 may not only differ from the value of $F 2$, by any difference at all, but also may not be connected with the latter at all. On the other hand, the sixth factor is much more important for assessing the effectiveness of the FCS, and that is why it is assigned a weight coefficient of 0.2 .

\section{DISCUSSION}

Public procurement form a single technological cycle, where the following are the mandatory elements:

- making forecasts to assess the volume and structure of procurement for state needs;

- planning the provision of state needs through purchases made by state customers, and also carried out by the latter;

- formation of specific orders, their placement, execution control, acceptance and monitoring of contract results, the results of which are used to optimize subsequent procurement operations.

The contract system, which at the moment has not yet completed the stage of full implementation, testing, and adjustment, was required for significant improvement in the 
quality of satisfying the needs of governmental structures, which became possible through the use of a systematic approach to planning, placing, and implementation control of government contracts. All this should serve as an incentive to develop and improve the entire Russian economy, improve the efficiency of managerial impact on technological and economic risks, and also promote the development of fair competition in the market.

The new federal contractual system has a number of advantages, which in essence are problems of the previous system, which were solved in the new law and its enforcement practice. Among such aspects, we consider it important to highlight the following:

- the customers in the new system can justify the needs for goods, work, services, estimated for the preparation of procurement plans, using the goals of procurement and cost standards in the coming budget period;

- despite the general focus on reducing budget expenditures, new anti-dumping measures allowed filtering out incoming bids with prices significantly lower than the initial ones, if there is any ground for considering them unreasonably underestimated;

- creation of a unified information system;

- introduction of a register of bank guarantees;

- standardization in the area of public procurement;

- possibility to involve experts;

- possibility public discussion;

- introduction of new mechanisms for the implementation of state orders;

- emergence of audit and monitoring in the field of procurement.

Of course, the new system is not without a number of widely recognized and discussed shortcomings. Basically, they are associated with the shortage of regulation rules on procurement procedures, including the unsatisfactory methods for selecting executors of the state order.

\section{CONCLUSION}

The procurement contract system for the needs of federal state unitary enterprises, which are essential for ensuring the rights and legitimate interests of citizens of the Russian Federation, the defense capability, and security of the state often includes mutually exclusive elements that must be balanced. This is the need to combine the openness and transparency of public procurement and at the same time keep secret the information that could be used later by a potential adversary against the Russian Federation, including the protection of state secrets.

The efficiency of spending budget funds directly depends on the strict implementation of all the procedures provided for by the contractual system in the area of procurement and the preparation of relevant documentation to ensure control over the quality of their implementation. The preparation of a significant amount of documents in conjunction with the regular change in the requirements for conducting procurement procedures greatly complicates the activities of state customers, and sometimes does not at all make it possible to solve the tasks assigned to them. While avoiding compliance with procurement procedures, in turn, makes it difficult to ensure economic efficiency and may cause offences.

\section{References}

[1] Federal law dated 5 April 2013, no. 44-FZ "Concerning the contractual system in the area of goods, work, service procurement for state and municipal needs", Legal website Consultant Plus, Retrieved from: http://www.consultant.ru (access date: 12.11.2019).

[2] A.G. Volkova, "The Problem Of Dividing The Power Of Authorities Of Different Levels In The Implementation Of The Budgetary Policy". Proc. conf., pp. 44-49, 2016, Voronezg.

[3] Federal law "Concerning alterations to certain legal acts of the Russian Federation in terms of purchasing goods, works, services state and municipal needs of specific types of legal entities" dated July 3rd, 2016 , \#321-FZ [Digital resource] // Legal website ConsultantPlus - Access at: http://www.consultant.ru (access date: 12.11.2019).

[4] Decree of the Government of the Russian Federation "Concerning the specifics of procurement for the needs of the national defense and security of the country" dated 27 November 2017, no. 1428 (with alternations and amendments), Legal website ConsultantPlus, Retrieved from: http://www.consultant.ru (access date: 12.11.2019).

[5] Federal law "Concerning alterations to the Federal law "Concerning the contractual system in the area of goods, work, service procurement for state and municipal needs" was enacted on December 31st, 2017, no. 504-FZ, Legal website ConsultantPlus, Retrieved from: http://www.consultant.ru (access date: 12.11.2019)

[6] K.I. Kremer, T.V. Sabetova, "Implementation Of The Non-Profitable Marketing Principles In Electronic Auctions For Public Procurement", Russ. J. of Agricult. and Socio-Econ. Sci., vol. 8, no. 56, pp. 152-162, 2016, DOI: 10.18551/rjoas.2016-08.19

[7] K.I. Kremer, T.V. Sabetova, "The Practice of Application of Various Methods of Public Procurement And The Assessment of Their Efficiency”, Econ. and Entrepreneurship, vol. 1-2, no. 66, pp. 99-103, 2016.

[8] B. Neto, "Analysis of sustainability criteria from European public procurement schemes for foodservices", Sci. of the total environment vol. 704, art. no. 135300, 2020, DOI: 10.1016/j.scitotenv.2019.135300

[9] I.Ju. Knyazeva, "Factors of Development of Russian Contractual System", Competitiveness. Innovat. Finance, no. 2, p. 16, 2014.

[10] N.V. Slinkova, A.G. Volkova, T.V. Sabetova, "Risks Of The Territorial Development Strategy Of The Agrarian Oriented Municipality”, Russ. J. of Agricult. and Socio-Econ. Sci., vol. 5, no. 65, pp. 60-66, 2017, DOI: 10.18551/rjoas.2017-05.09 